\title{
L3 acquisition of English present perfect
}

Sviatlana Karpava

University of Central Lancashire, Cyprus, Cyprus Acquisition Team

https://doi.org/10.36505/ExLing-2015/06/0007/000244

\begin{abstract}
This study investigates L3 acquisition of English present perfect by Greek Cypriot speakers. One hundred CG university students took part in the study, the first part of which examined the sensitivity to grammatical norms (a passage correction task, based on Odlin et al., 2006), and the other part was focused on the production of English present perfect (elicitation of natural discourse, essays about personal experience). The results showed that L3 learners used more non-target tense forms (present simple and past simple) than the target present perfect in obligatory contexts, which is due to transfer from L1 CG. The findings are in line with the Typological Primacy Model (Rothman, 2010), as L3 learners transfer from L1 and this transfer is negative.
\end{abstract}

Key words: present perfect, L3 acquisition, L1 transfer, pragmatic conditions

\section{The Study}

According to the Typological Primacy Model (TPM) (Rothman, 2010), proximity in actual or perceived linguistic typology is the most important in adult multilingual syntactic transfer (Rothman and Cabrelli Amaro, 2007; Rothman, 2010). Both L1 and L2 can be a source for transfer in L3/Ln, dependent upon typological and psychotypological similarities between target L3 and L1 or L2. Psychotypology is the speaker's perception of typological proximity between languages (Kellerman, 1983). TPM is in line with the Full Transfer/Full Access Hypothesis. Transfer occurs selectively and it can be both positive and negative.

With regard to current research, semantic and pragmatic conditions compatible with present perfect are different in CG, SMG and English, so it is expected that L3 learners would fail to notice these conditions. They might have a tendency to use past simple instead of existential present perfect due to transfer from L1 CG. They might overlook these semantic and pragmatic conditions related to present perfect, as in their L1 there are no such meanings and conditions and, as a result, would equate the semantics of present perfect with semantics of past simple. The aim of this study is to reveal the cause of non-target/deviant production of L3 English present perfect, the direction and the source of transfer to L3, and the role of semantic/pragmatic contexts of the present perfect, lexical aspect, transitivity of the verb, type of the sentence, type of the adverbial modification as well as the role of age, age of onset and the length of L3 input on the comprehension and production of English present perfect.

ExLing 2015: Proceedings of 6th Tutorial and Research Workshop on Experimental Linguistics, 26-27 June 2015, Athens, Greece 


\section{Study}

100 CG university students (89 undergraduate, 11 postgraduate) took part in the study (69 males and 31 females, age: $17-36$ years, length of exposure to L3 input: 2-20 years, age of onset to L3: 10 to 27 years). The first part of the study examined the sensitivity to grammatical norm (a passage correction task), while the other part of the study was focused on the actual production of English present perfect (elicitation of natural discourse). The proofreading test based on Odlin et al. (2006) had 60 test items (25 errors: present perfect, resultative and existential, replaced with present simple and past simple and 35 distractors: correct and incorrect usage of present simple/continuous, past simple/continuous, future simple).

\section{Results and Discussion}

The analysis of the error correction task showed that only $400(16 \%)$ of all errors were corrected and L3 learners used target present perfect, the other errors $(2100 / 84 \%)$ were either not corrected or L3 learners tended to use other non-target tense forms instead of present perfect: past simple (1154/46.16\%), past perfect $(6 / 0.24 \%)$, past continuous (36/1.44\%), present simple $(809 / 32.36 \%)$ or present continuous $(95 / 3.80 \%)$. L2 learners had more "no changes' for past simple test items $(63.76 \%)$ than for present simple test items $(48.41 \%)$, with both past simple and present simple test items having the same percentage of changes to present perfect (17\% and 16.33\%). Present simple test items were more changed to past simple $(29 \%)$ than past simple test items were changed to present simple $(17.33 \%)$. Consequently, the most preferable tense used instead of present perfect is past simple, see Table 1:

Table 1. (No) attempted corrections of test items.

\begin{tabular}{|c|c|c|}
\hline & Past simple items & Present simple items \\
\hline No changes & $829(63.76 \%)$ & $581(48.41 \%)$ \\
\hline \multicolumn{3}{|l|}{ Changed to } \\
\hline Present perfect & $221(17 \%)$ & $196(16.33 \%)$ \\
\hline Past perfect & $7(0.53 \%)$ & $3(0.25 \%)$ \\
\hline Present simple & $225(17.33 \%)$ & \\
\hline Present continuous & $18(1.38 \%)$ & $47(3.93 \%)$ \\
\hline Past continuous & & $25(2.08 \%)$ \\
\hline Past simple & & $348(29 \%)$ \\
\hline
\end{tabular}

No significant difference was revealed between target production for existential and perfective present perfect. But L3 learners of English used more past simple for existential present perfect $(50.44 \%)$ than for resultative present perfect $(38.70 \%$ ). This can be due to transfer from L1 CG (usage of past simple instead of existential present perfect). They used more present simple for 
resultative present perfect $(39.60 \%)$ than for existential present perfect $(27.46 \%)$. These findings are in line with the Typological Primacy Model (Rothman, 2010), as L3 learners transfer from L1 CG. This transfer is negative, non-facilitative, and CG is psychologically perceived to be typologically closer to English (than SMG to English) due to the post-colonial situation in Cyprus and widespread usage of English on the island. Overall, L3 learners showed better production for distractor items than for test items. This suggests that they have a particular problem with present perfect rather than with other tenses (present simple/continuous, past simple/continuous, future simple). They had a higher percentage for acceptance of the correct distractor items $(75.85 \%)$ than for the correction of incorrect distractors (52.34\%).

A paired samples t-test showed a statistically significant difference between target and non-target present perfect production $(\mathrm{t}(99)=14.992, \mathrm{p}=.000)$, target present perfect and non-target past simple production $(\mathrm{t}(99)=8.060, \mathrm{p}=.000)$, target and non-target distractor production $(\mathrm{t}(99)=9.338, \mathrm{p}=.000)$, and present perfect and past simple production in existential contexts $(\mathrm{t}(99)=8.713$, $\mathrm{p}=.000)$. One-way ANOVA showed that age, length of exposure to L3, and gender are not crucial factors for L3 present perfect production. Pearson correlation analysis showed that target and non-target present perfect production is correlated with target and non-target distractor production (proficiency): Sig 2-tailed .000. Thus, L3 proficiency is the crucial factor for target/non-target L3 present perfect production.

With regard to elicitation of natural discourse: discourse about personal experiences based on essays, overall, it was very difficult to elicit present perfect in natural discourse due to the low rate of present perfect production (151 obligatory present perfect contexts for 100 essays). It was found that L3 learners used more non-target tense forms (64.91\%): past simple $(45.05 \%)$ or present simple (19.86\%), than target present perfect (35.09\%) in the obligatory present perfect contexts. They used both present and past simple instead of present perfect due to similarities of certain features of present perfect and present simple (current relevance) and present perfect and past simple (anterior) (Bardovi-Harlig, 1997).

It was found that target present perfect was used mainly in resultative contexts, while non-target past simple was used both in resultative and experiential/existential contexts, and non-target present simple was used in resultative, extended-now and recent past. It seems that the semantic context of present perfect influences target and non-target production of present perfect in L3 English. Cypriot Greek students tend to use past simple instead of present perfect in existential/experiential contexts, which can be explained by L1 transfer, as in CG they use past simple instead of experiential/existential present perfect. Target present perfect was mainly used with achievement verbs, non-target past simple was used both with achievement and state verbs, and non-target present simple was used with achievement, state and activity 
verbs. The data supports the Inherent Lexical Aspect Hypothesis (Andresen and Shirai, 1996; Bardovi-Harlig, 1999), as L3 learners use mainly achievement and accomplishment verbs with perfective and past tense morphology.

This study is an attempt to shed light on multilingual development - L3 acquisition of English in Cyprus with regard to present perfect. Both comprehension and production of this particular linguistic phenomenon have been examined. It was found that L3 learners transfer from L1 CG rather than from L2 SMG, specifically using past simple instead of existential present perfect. L3 learners ignore semantic and pragmatic conditions compatible with the use of English present perfect; they mostly equate the semantics of the past tense with the semantics of the present perfect. This is in line with the Typological Primacy Model (Rothman, 2010), as this transfer is non-facilitative and there is also a (psycho)-typological proximity between CG and English.

\section{References}

Andersen, R. and Shirai, Y. 1996. Primacy of aspect in first and second language acquisition: The pidgin/creole connection. In T.K. Bhatia and W. Ritchie (eds.), Handbook of Second Language Acquisition, 527-570. London, Academic Press.

Bardovi-Harlig, K. 1997. Another piece of the puzzle: The emergence of the present perfect. Language Learning 47, 375-422.

Bardovi-Harlig, K. 1999. Exploring the interlanguage of interlanguage pragmatics: A research agenda for acquisitional pragmatics. Language Learning 49, 449-65.

Kellerman, E. 1983. Now you see it, now you don't. In Gass, S. and Selinker, L. (eds.), Language Transfer in Language Learning, 112-134. Rowley, MA, Newbury House.

Odlin, T., Alonso, R. and Alonso-Vazquez, C. 2006. Fossilization in L2 and L3. In Han, Z.H. and Odlin, T. (eds.), Studies of Fossilization in Second Language Acquisition, 56-83. Clevedon, England, Multilingual Matters.

Rothman, J. 2010. On the typological economy of syntactic transfer. International Review of Applied Linguistics (IRAL) 48, 243-71.

Rothman, J. and Cabrelli, J. 2007. On the initial state of L3 (Ln) acquisition: Selective or absolute transfer? Paper presented at the 5th International Conference on Third Language Acquisition, Stirling, Scotland, September. 